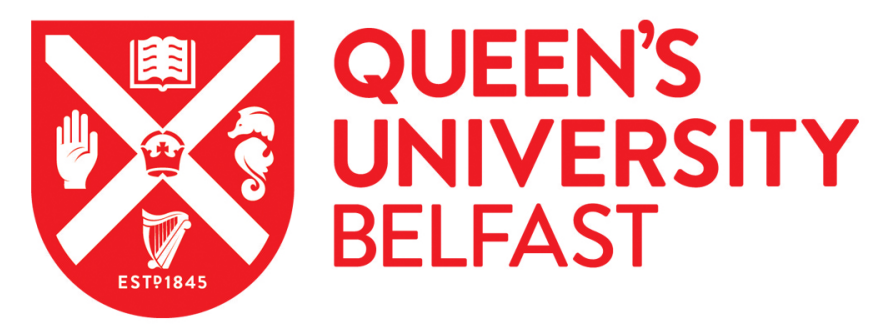

\title{
Synthesis, characterisation and study of magnetocaloric effects (enhanced and reduced) in manganate perovskites.
}

McBride, K., Partridge, N., Bennington-Gray, S. ., Felton, S., Stella, L., \& Poulidi, D. (2017). Synthesis, characterisation and study of magnetocaloric effects (enhanced and reduced) in manganate perovskites. Materials Research Bulletin, 88, 69-77. https://doi.org/10.1016/j.materresbull.2016.12.019

Published in:

Materials Research Bulletin

Document Version:

Peer reviewed version

Queen's University Belfast - Research Portal:

Link to publication record in Queen's University Belfast Research Portal

Publisher rights

(c) Elsevier Ltd. This manuscript version is made available under the CC-BY-NC-ND 4.0 license http://creativecommons.org/licenses/by-nc$\mathrm{nd} / 4.0 /$, which permits distribution and reproduction for non-commercial purposes, provided the author and source are cited.

\section{General rights}

Copyright for the publications made accessible via the Queen's University Belfast Research Portal is retained by the author(s) and / or other copyright owners and it is a condition of accessing these publications that users recognise and abide by the legal requirements associated with these rights.

Take down policy

The Research Portal is Queen's institutional repository that provides access to Queen's research output. Every effort has been made to ensure that content in the Research Portal does not infringe any person's rights, or applicable UK laws. If you discover content in the Research Portal that you believe breaches copyright or violates any law, please contact openaccess@qub.ac.uk. 


\section{Synthesis, characterisation and study of magnetocaloric effects (enhanced and reduced) in manganate perovskites.}

K. McBride ${ }^{a^{*}}$, N. Partridge ${ }^{a}$, S. Bennington-Gray ${ }^{b}$, S. Felton ${ }^{b}$, L. Stella ${ }^{a, b}$ and D.

Poulidia,

a. School of Chemistry and Chemical Engineering, Queen's University Belfast, Stranmillis Road, Belfast BT9 5AG, UK

b. School of Mathematics and Physics, Queen's University Belfast, University Road, Belfast BT7 1NN, UK

*kmcbride11@qub.ac.uk

\section{Highlights}

- $\mathrm{La}_{1-\mathrm{x}} \mathrm{Ca}_{x} \mathrm{MnO}_{3}$ and $\mathrm{La}_{1-\mathrm{x}} \mathrm{Ba}_{x} \mathrm{MnO}_{3}$ synthesised using the modified peroxide sol-gel synthesis.

- Enhanced magnetic heating for manganates doped with A-site cations larger than La ${ }^{3+}$.

- Reduced magnetic heating observed for manganates doped with A-site cations smaller than $\mathrm{La}^{3+}$. 


\section{Abstract}

The effect of the A-site dopant ionic radii on the observed magnetocaloric effect (MCE) exhibited by three different families of manganese-based perovskites was investigated using both induction heating and SQUID magnetometry measurements. The doped perovskites La 1${ }_{x} \mathrm{Sr}_{x} \mathrm{MnO}_{3}(\mathrm{LSMO}), \mathrm{La}_{1-\mathrm{x}} \mathrm{Ca}_{x} \mathrm{MnO}_{3}(\mathrm{LCMO})$, and $\mathrm{La}_{1-\mathrm{x}} \mathrm{Ba}_{\mathrm{x}} \mathrm{MnO}_{3}(\mathrm{LBMO})(\mathrm{x}=0.25,0.35,0.4)$ were prepared using a modified peroxide sol-gel synthesis. This method has not been previously used for the synthesis of LCMO or LBMO. Structural characterisation of the agglomerates of magnetic nanoparticles (MNP) for each material was carried out using SEM, XRD and IR spectroscopy. Magnetic heating was observed for materials with larger A-site dopant radii relative to $\mathrm{La}^{3+}$; LSMO40 and LBMO40, with average SARs obtained of $51.5 \mathrm{Wg}^{-1} \mathrm{Mn}$ and 33.8 $\mathrm{Wg}^{-1} \mathrm{Mn}$ respectively. However, reduced magnetic heating effects were observed for smaller A-site dopant radii relative to $\mathrm{La}^{3+}(\mathrm{LCMO})$. In fact, the calculated Specific Absorption Rate for $\mathrm{LCMO} 40$ of $14.72 \mathrm{Wg}^{-1} \mathrm{Mn}$ is half that of the blank.

\section{Key Words}

A. magnetic materials; B. intercalation reaction; B. magnetic properties; C. X-ray diffraction;

D. crystal structure. 


\section{Introduction}

Mixed metal oxides with a perovskite-type crystalline structure are of interest in a variety of fields. Investigations have been conducted into areas of application such as fuel cell catalysis ${ }^{1}$, superconductors ${ }^{2}$, dye-sensitized solar cells (DSSCs) ${ }^{3}$, and mediators in hyperthermia treatment for cancer ${ }^{4}$. The physical and chemical properties of these materials depend on their perovskite crystal structure. The ideal metal oxide perovskite structure is of the type $\mathrm{ABO}_{3}$ with cubic geometry as shown in Figure 1 (b). In this structure, the A site cation $\left(\mathrm{La}^{3+}\right)$ is larger than the central B site cation $\left(\mathrm{Mn}^{3+}\right)$ and it occupies the corners of the unit cell. This structure can be modified through the substitution of ions, or doping. By controlling the doping, one can fine tune some physical and chemical properties of the perovskites to target a particular application.

Figure 1 (c) shows the doping of the $\mathrm{ABO}_{3}$ crystal structure with an A-site cation larger than $\mathrm{La}^{3+}$ such as $\mathrm{Sr}^{2+}$ in the case of the $\mathrm{La}_{1-x} \mathrm{Sr}_{x} \mathrm{MnO}_{3}$ (LSMO) family of perovskites. Their structures have been previously investigated for a variety of compositions. ${ }^{5-8}$ In this instance, $\mathrm{La}^{3+}$ or $\mathrm{Sr}^{2+}$ ions occupy the A-site and either $\mathrm{Mn}^{3+}$ or $\mathrm{Mn}^{4+}$ occupies the B-site. As found in a previous work by this group, an increase of the relative weight percentage of the orthorhombic (Pnma) crystalline phase is observed by increasing the strontium dopant in the LSMO synthesised using a modified peroxide sol-gel method. ${ }^{8}$ This structural change upon doping can cause a huge variation of the Curie temperature $\left(T_{c}\right)$. For example, increasing the dopant from $x=0.1$ to 0.2 increases the $T_{c}$ from $-13{ }^{\circ} \mathrm{C}$ to $77^{\circ} \mathrm{C} .{ }^{9}$ This change in $T_{c}$ with structure meant that LSMO at a variety of dopant levels exhibited enhanced magnetic heating properties compared with the parent compound. ${ }^{8}$ 
Figure $1(\mathrm{a})$ and $(\mathrm{c})$ show the effect of substituting the A-site cation, $\mathrm{La}^{3+}$ (cationic radii of $1.36 \AA ̊$ ) with smaller $\left(\mathrm{Ca}^{2+}\right)$ or larger $\left(\mathrm{Sr}^{2+}\right.$ or $\left.\mathrm{Ba}^{2+}\right)$ cations (cationic radii of 1.34, 1.44 or $1.61 \AA$ A respectively $)^{10}$ on the structure of the parent perovskite unit cell (1b). As with LSMO, the substitution of a cation for one of differing size (either larger or smaller than $\mathrm{La}^{3+}$ ) will result in a distortion of the crystal structure. This distortion leads to the alteration of bond angles and bond lengths, which in turn affects the magnetic properties of the material (such as the magnetic susceptibility and magnetocaloric effect).

The magnetic properties of manganates arise from a double exchange mechanism. ${ }^{11}$ The strength of the mechanism is determined by two main factors: the oxidation state of manganese and the bond angle formed by the manganese cations and the oxygen anion between them. In particular, the double exchange mechanism is most prominent in manganates where the angle is flat and there is maximal overlap of the $\mathrm{Mn}^{3+}-\mathrm{O}^{2-}-$ $\mathrm{Mn}^{4+}$ bonding $\mathrm{d}$ - and $\mathrm{p}$ - orbitals. ${ }^{11}$ The magnetic properties of interest in this work are magnetic susceptibility and magnetocaloric effect (MCE). The origin of the MCE is ultimately associated with the dependence of the magnetic entropy on both temperature and external magnetic field. As a consequence, the magnetic nanoparticles can heat up or cool down in response to a change of the field. By using an alternating magnetic field and tuning its frequency appropriately, one can also exploit a resonance in the (complex) magnetic susceptibility to maximise the heat dissipated during the magnetic process.

When a magnetic field is applied to a ferromagnetic material, three types of dissipative magnetic response are relevant for nanoparticles: Neél rotations, Brownian rotations or hysteresis. Neél rotations are internal rotations where there is 
realignment of magnetic moments within a particle under the influence of an external magnetic field with respect to the crystal structure. The excess energy absorbed during the realignment is dissipated through an internal friction mechanism. Brownian rotations are external rotations whereby the entire molecule rigidly realigns with the external magnetic field, causing friction between the molecule and the surrounding medium. These first two mechanisms are especially relevant for single-domain nanoparticles. When several magnetic domains are present, the material exhibits the typical 'hysteresis loop' with the energy dissipated in the process proportional to the loop area. ${ }^{12}$ The three dissipative response mechanisms of a nanoparticle are associated with an overall positive change of the particle temperature (enhanced magnetocaloric effect). In the right range of temperatures, the heat generated can induce a first order phase transition associated with a change of magnetic (e.g. ferromagnetic to paramagnetic) and crystal structure (e.g. orthorhombic to rhombohedral). ${ }^{13,14}$ In this instance, the latent heat necessary for the phase transition will not be dissipated and the overall temperature will increase to a smaller extent (reduced magnetocaloric effect). This may even manifest as an apparent drop in temperature compared to the blank.

We are particularly interested in developing materials which exhibit a positive MCE with enhanced magnetic heating to develop more effective mediators for magnetic fluid hyperthermia (MFH). MFH is a targeted treatment for cancer whereby a magnetic material in the presence of an alternating magnetic field causes a local temperature increase in the mild hyperthermia range of $41-46^{\circ} \mathrm{C}$. In the mild hyperthermia range, cancerous tissue will be selectively damaged over healthy tissue. LSMO has already 
been investigated as a suitable potential mediator for $\mathrm{MFH},{ }^{5-8}$ but to the knowledge of the authors, little consideration has been given to other perovskite manganates.

In our previous work ${ }^{8}$ we identified links between the crystal structure changes (as a result of the dopant concentration on the A-site of LSMO) and the magnetic properties of the resulting nanoparticle clusters. In this work we aim to investigate the effect of the A-site doping radii on the observed MCE of perovskite manganates as a means to improving material design. To this effect, various compositions $(x=0.25,0.35$ and 0.4 ) of the manganate perovskites $\mathrm{La}_{1-\mathrm{x}} \mathrm{Sr}_{\mathrm{x}} \mathrm{MnO}_{3}(\mathrm{LSMO}), \mathrm{La}_{1-\mathrm{x}} \mathrm{Ca}_{x} \mathrm{MnO}_{3}$ (LCMO), and $\mathrm{La}_{1-\mathrm{x}} \mathrm{Ba}_{\times} \mathrm{MnO}_{3}$ (LBMO) were prepared via a modified peroxide sol-gel synthesis. ${ }^{15-}$ 17 This method has not been employed in the synthesis of LCMO or LBMO before. However LSMO has been prepared using this method as described in our previous work. ${ }^{8}$ The use of a sol-gel synthesis is advantageous as it not only yields agglomerates of nanoparticles which are more appropriate for in-vivo $\mathrm{MFH}^{6}$, but the variation in crystallite size with this type of synthetic approach will influence the contribution of magnetic hysteresis to the magnetocaloric effect. ${ }^{7}$ The structural modifications to the perovskite structure caused by replacing $\mathrm{La}^{3+}$ with various dopants $\left(\mathrm{Ca}^{2+}, \mathrm{Ba}^{2+}\right.$ or $\left.\mathrm{Sr}^{2+}\right)$, along with the subsequent effects on the magnetic properties (MCE, magnetic susceptibility and hysteretic losses) of the material are investigated in this work. Alkaline earth metal cations $\left(\mathrm{Ca}^{2+}, \mathrm{Ba}^{2+}\right.$ or $\left.\mathrm{Sr}^{2+}\right)$ were chosen as dopants so as to investigate the effect of cationic radii on the crystal structure, rather than the $\mathrm{Mn}^{3+} / \mathrm{Mn}^{4+}$ ratio.

We have chosen to observe the MCE directly from induction heating experiments. The observations are supported by direct magnetic measurements to better represent potential applications. Our approach is also motivated by Phan et al. who highlight the 
accumulation in experimental errors in the total entropy functions near room temperature. ${ }^{18}$ They state that errors for direct and indirect MCE measurements are approximately the same in this temperature range. Thus we have chosen to present the direct $\mathrm{MCE}$, in addition to magnetisation data.

\section{Experimental}

\subsection{Material Synthesis}

Table 1 shows the desired stoichiometry and sample codes for the synthesised samples, along with the characterisations presented in this work. Details of the modified sol-gel method used previously by this group for the synthesis of LSMO can be found elsewhere. ${ }^{8}$ In this work, the synthesis of LCMO and LBMO involve the use of the following powder precursors: barium carbonate $\left(\mathrm{BaCO}_{3}\right), 99 \%$ purity; calcium carbonate $\left(\mathrm{CaCO}_{3}\right)$, 99\% purity; lanthanum (III) oxide, $\geq 99.9 \%\left(\mathrm{La}_{2} \mathrm{O}_{3}\right)$; manganese(II) carbonate $-\geq 99.9 \%$ trace metals basis; strontium carbonate $h-\geq 99.9 \%$ trace metals. The precursors were all obtained from Sigma Aldrich and used without any pretreatments.

\subsection{Characterization}

The stoichiometry of the samples were determined with energy-dispersive X-ray spectroscopy (EDX) using Aztec version 2.0 software in an eSEM - FEI Quanta FEGEnvironmental SEM Oxford Ex-ACT at an accelerating voltage of $20 \mathrm{kV}$. The morphology 
of the samples was studied using secondary electrons in the same instrument also at an accelerating voltage of $20 \mathrm{kV}$.

X-ray diffraction (XRD) (Panalytical X'Pert PRO) with CuKa1 radiation source of wavelength $\quad 1.540598 \AA$ and Fourier Transform Infrared Spectroscopy (FTIR Perkin Elmer Spectrum 2) were used for structural determination with High Score Plus software ${ }^{19}$ used for the analysis of the results. The Rietveld analyses were conducted using X'Pert High Score Plus on the diffraction patterns with a view to elucidate the proportion of different crystalline phases present in the powder samples. Many parameters for crystal structure geometries were individually trialled (e.g. Pnma, R-3c, Pmcn, Imma, etc.) using Rietveld analysis on parameters from literature to identify the individual crystal structures contained within the polycrystalline material. Once suitable crystal structures which best suited the diffraction patterns were identified (Pnma and R-3c), a combined multi-phase Rietveld analyses was conducted to quantify the proportions of each crystal structure. The values in Tables $2 a$ ) and $2 b$ ) are the individual crystal structures from literature which best match the diffraction patterns in this work (in terms of reflections and intensities) and were therefore used in the quantification of the whole pattern. The background was not subtracted. Refinement of the atomic coordinates and unit cell parameters of both phases was undertaken before refining the instrumental parameters. Bond angles were not allowed to vary in the refinements. Following Rietveld refinement of the diffraction patterns, the Scherrer equation was used to determine the size of the crystallites presented in Table 3 using the most intense reflection for each crystal phase (but common to all materials). We therefore used the (002) reflection for the Pnma crystal phase and the (104) reflection for the R-3c crystal phase. These reflections occurred at 
approximately $32^{\circ} 2 \theta$ with a calculated error of $\pm 0.1 \mathrm{~nm}$ in keeping with the values quoted.

Magnetic measurements including magnetic susceptibility and hysteresis were measured using a superconducting quantum interference device (SQUID) magnetometer (Quantum Design MPMS XL SQUID Magnetometer, 7 T and 1.9 to 400 K). The hysteresis loops were generated by changing $\mathrm{H}$ over a range between $-10,000$ and 10,000 Oe and at 100 and $200 \mathrm{~K}$. Susceptibility measurements were conducted in field cooled (FC) and zero field cooled (ZFC) conditions between 100 and $370 \mathrm{~K}$ and 500 Oe.

Heating experiments were conducted using an AC generator (Easyheat 0112) with a water-cooled induction coil (6-turn $12 \mathrm{~cm}$ length coil). A set current of $219 \mathrm{~A}$ was used, which for this system generated a frequency of $175 \mathrm{kHz}$ and a magnetic field strength of $137.6 \mathrm{Oe}\left(10.95 \mathrm{kA} \mathrm{m}^{-1}\right)$. Temperature measurements were recorded using an IR temperature probe (Optocon AG) FOTEMP 1 coupled to a (Optocon AG) TS2/2 sensor. Aqueous suspensions of the powders in plastic sample bottles were used at a suspension concentration of $5 \mathrm{mg} \mathrm{mL}^{-1}$. The sample bottles were insulated in polystyrene during the heating experiments. The Specific Absorption Rate (SAR) was calculated for each material based on the induction heating data. The SAR is estimated using the following corrected slope method equation using Wildeboer et.al's method $^{20}$ :

$S A R_{\text {corrected slope }}=\frac{c_{w} \frac{\Delta T_{w}}{\Delta t}+l \Delta T_{w}}{m_{M N P}}$ 
where $\boldsymbol{c}_{\mathrm{w}}=$ specific heat capacity $\left(\mathrm{J} \mathrm{g}^{-1} \mathrm{~K}^{-1}\right)$ of water, $\boldsymbol{m}_{\boldsymbol{M N P}}=$ weight fraction of the magnetically active element, $\frac{\Delta \boldsymbol{T}_{\boldsymbol{w}}}{\Delta \boldsymbol{t}}=$ change in temperature of the water against time, $\boldsymbol{l}$ $=$ thermal losses of the system.

As we found in a previous work, the large currents flowing through the induction coil caused additional heating of the sample. ${ }^{8}$ In particular, an increase of 3 ${ }^{\circ} \mathrm{C}$ over a 10 minute period has been consistently observed for the same volume of pure water without magnetic nanoparticles (the "blank"). ${ }^{20}$ In fact, the blank acts as a standard to define either an enhanced (e.g., more than the blank) or reduced (e.g., less than the blank) magnetic heating effect during the experiments. The blank is particularly useful for the reduced magnetic heating which may otherwise go unnoticed. The magnetic heating curves are not corrected in this instance to remove the blank heating profile in keeping with the conventional presentation of results for the observation of positive MCE effect using induction heating experiments. We have, however, taken the blank into consideration at each stage by showing it in the heating curves and also by calculating the SAR of the blank to use as a comparison for the range of materials investigated in this work. In our previous work, optimal magnetic heating was observed for LSMO with $\mathrm{x}=0.35 .^{8}$ The main characterisation of crystal structure and magnetic properties presented in this work is however on LSMO, LCMO, and LBMO where $x=0.4$. This dopant level was chosen as all of the materials showed a departure in magnetic heating properties (enhanced or reduced) compared with the blank.

\section{Results and Discussion}

\subsection{Crystalline structure and configuration analysis}


Table 1 shows the stoichiometry of the synthesised samples verified using EDX, which were found to be in range of the desired ratios (the EDX maps of all samples are provided in the Supplementary Information Figures 1 to 3 ). Figure 2 shows the XRD patterns of the manganate materials prepared using this modified peroxide sol-gel synthesis. In Figure 2 the doped $\mathrm{La}_{0.6} \mathrm{Sr}_{0.4} \mathrm{MnO}_{3}$ (LSMO40), $\mathrm{La}_{0.6} \mathrm{Ba}_{0.4} \mathrm{MnO}_{3}$ (LBMO40) and $\mathrm{La}_{0.6} \mathrm{Ca}_{0.4} \mathrm{MnO}_{3}$ ( $\mathrm{LCMO} 40$ ) samples are compared to the rhombohedral $\mathrm{R}-3 \mathrm{C}$ polymorph of lanthanum manganate (LMO) synthesised using the same method. From Figure 2 we can see that based on the common reflections, the rhombohedral geometry of the perovskite parent compound LMO is evident in dominant crystal phases for the various doped manganates. The presence of more than one stoichiometric crystalline phase for LSMO40 is evident in the shallow transition in magnetic susceptibility vide infra. These variations in local stoichiometries were not able to be identified either by trialling different model stoichiometries in the Rietveld analysis, or by using EDX. Other potential secondary phases which may be present in even smaller amounts include $\mathrm{La}_{2} \mathrm{O}_{3}, \mathrm{MnCO}_{3}$ and $\mathrm{SrMnO}_{3}{ }^{21}$

Rietveld analysis results summarised in Table 3 confirmed that the $\mathrm{Ca}$, $\mathrm{Sr}$, and Ba-doped lanthanum manganates synthesised via this method are rhombohedral (R3c) and orthorhombic (Pnma) polymorphs. The Rietveld analyses for the materials in Table 3 are shown in the Supplementary Information. Slobodin et al. found reduced orthorhombic distortion and higher symmetry crystal structures caused by increasing $\mathrm{Mn}^{4+}$ content and also the substitution of $\mathrm{La}^{3+}$ for a larger sized cation on the A-site for doped lanthanum manganates. ${ }^{22}$ From the quantification of crystalline phases using Rietveld analysis as depicted in Table 3, we have also found a reduction of the orthorhombic phase with increasing dopant radii compared to $\mathrm{La}^{3+}$. The increase in 
average A-site cationic radii from LCMO40 to LSMO40 and LBMO40 is seen to favour the rhombohedral $\mathrm{R}-3 \mathrm{c}$ crystal structure, with an increase in the relative weight percentage for this phase. As would be expected, the increasing size of the average Asite cationic radii causing the increase in cell volume can also be seen in Table 3 when comparing LCMO40 to LSMO40 and LBMO40. Figure 3 shows the micrographs of the prepared samples which consist of agglomerates of nanoparticles of the order of 10 $\mu \mathrm{m}$ for the LSMO40 material (Figure 3b), but slightly smaller for the LBMO40 (Figure 3a) and LCMO40 (not shown here) samples.

Figure 4 shows the FTIR analysis for the prepared manganate samples. The presence of octahedral $\mathrm{MnO}_{6}$ revealed by the absorption at approximately $600 \mathrm{~cm}^{-1}$ by the $\mathrm{Mn}-\mathrm{O}$ bond can be seen in all cases. LSMO40 has a characteristic $\mathrm{Mn}-\mathrm{O}$ absorbance of higher wavenumber than LBMO40 and LCMO40. The relationship between mass and wavenumber is derived from Hooke's Law:

$\tilde{v}=\frac{1}{2 \pi c} \sqrt{\frac{k}{\mu}}$

where $\tilde{v}=1 / \lambda, k$ is the force constant, and $\mu$ is the reduced mass of the system where $\mu=\frac{m_{1} m_{2}}{m_{1+} m_{2}}$. We would expect that as the crystal structure changes with dopant, variations in bond lengths and bond angles would occur, altering the degree of orbital overlap and affecting bond order. As a result, the force constant would change in each case and variations in absorption wavenumbers would occur. In this case, the reduced mass for the absorption wavenumber of the $\mathrm{Mn}-\mathrm{O}$ bond remains constant between the LCMO40, LBMO40 and LSMO40 samples. This means that the increase in vibrational frequency which we see for LSMO40 must be as a result of an increase in the force constant. As 
the force constant is a measure of the bond order, we can use it to infer the extent of the double-exchange mechanism present in the $\mathrm{Mn}-\mathrm{O}$ bond, and hence the extent of observed magnetic properties such as magnetocaloric effect. In our previous work, it was observed that samples with IR absorptions at greater wavenumbers for the $\mathrm{Mn}-\mathrm{O}$ bond exhibited a greater MCE when excited in an applied magnetic field. ${ }^{8}$ Thus we expected to see that when these samples would be placed in an applied field, the MCE in increasing order would be LCMO40, LBMO40 and LSMO40.

The relative dependence of crystallite diameter and the characteristic wavenumber of the $\mathrm{Mn}-\mathrm{O}$ bond on the average $\mathrm{A}$-site cationic radii was investigated using Figure 5. The mean average of Pnma and R-3c crystallite diameters was used to compare the crystallite diameters of the materials (LCMO40, LBMO40 and LSMO40). Figure 5 indicates that a high energy $\mathrm{Mn}-\mathrm{O}$ bond may exist where there is a small difference in cationic radii ( $2.4 \%$ as in the case of LSMO) along with a larger average crystallite diameter (approximately $26.95 \mathrm{~nm}$ ). It is important to note that this is a narrow study where we are looking at three different dopant ions $\left(\mathrm{Ca}^{2+}, \mathrm{Sr}^{2+}\right.$ and $\left.\mathrm{Ba}^{2+}\right)$ and that we may also be dealing with slight variations of the synthesis process for different batches leading to different crystallite sizes, so we will look for significant relationships.

We do not observe a direct correlation between the average A-site cationic radii and the crystallite diameter (LBMO40, LCMO40, LSMO40 in order of increasing crystallite diameter). We previously saw that increasing average A-site cationic radii from LCMO40 to LSMO40 and LBMO40 is seen to favour the rhombohedral R-3c crystal structure. However, when we look at the relationship between either the average A- 
site cationic radii or the crystallite diameter, and the characteristic wavenumber of the $\mathrm{Mn}-\mathrm{O}$ bond, we see that crystallite diameter appears to be a more determining parameter. LSMO40 with a much larger average crystallite diameter than either LCMO40 or LBMO40, has a much greater characteristic wavenumber of the $\mathrm{Mn}$-O bond than the other materials. With the exception of $\mathrm{LSMO}^{\circ}{ }^{8}$, these materials (LBMO and LCMO) have not been synthesised previously via this modified peroxide sol-gel method, so direct comparison cannot be made with literature. In order to elucidate whether the average A-site cationic radii may have an effect on the crystallite diameter of a material and lead to the existence of a high energy $\mathrm{Mn}-\mathrm{O}$ bond, further work may involve choosing a dopant combination where there is a small difference in cationic radii $(2.4 \%$ as in the case of LSMO) along with a larger average crystallite diameter (approximately $27 \mathrm{~nm}$ ).

\subsection{Magnetic heating experiments}

The heating curves for the $5 \mathrm{mg} \mathrm{mL}^{-1}$ aqueous suspensions of the materials with dopant $x=0.4$ are shown in Figure $6(a)$. They all show a monotonic behaviour with a linear initial heating followed by a final saturation. We have chosen the $x=0.4$ dopant to compare the materials here as all of the materials showed a departure in magnetic heating properties (enhanced or reduced) compared with the blank at this dopant level.

The heating curves for this group of materials showed the best separation for comparison. The heating curve (Supplementary Figure 5) of the anti-ferromagnetic ${ }^{23}$ (at room temperature) parent compound LMO, is almost indistinguishable from the 
blank curve. Hence we have attributed any variation of the heating profiles from the blank as being due to the dopant A-site cation. From Figure 6 we can see that both the gradients and saturation temperatures for the heating curves in increasing order are LCMO40, LBMO40 and LSMO40. This order is in agreement with our prediction in 3.1 based on the $\mathrm{Mn}-\mathrm{O}$ bond absorption frequency.

In Figure 6(b) the blank has been subtracted from the heating curves for LCMO40, LBMO40 and LSMO40. We can identify the materials doped with a larger Asite cation than $\mathrm{La}^{3+}, \mathrm{LSMO} 40$ and LBMO40 as exhibiting an enhanced magnetic heating effect. Both show a significant increase in temperature compared with the blank. Interestingly, LCMO40 which is doped with a smaller A-site cation than $\mathrm{La}^{3+}$ exhibits reduced magnetic heating or relative magnetic cooling, with a considerable decrease in temperature compared with the blank. The SARs for all of the materials are reported in Figure 7. LSMO and LBMO materials at dopants $x=0.25,0.35$ and 0.4 appear to have higher SARs than the other materials investigated as was expected from the higher characteristic wavenumber of the $\mathrm{Mn}-\mathrm{O}$ bond discussed with reference to Figure 5 . This is further illustrated by Figure 8 which shows the relationship between the wavenumber of absorption by the $\mathrm{Mn}-\mathrm{O}$ bond with the SAR directly.

From the theory of the double-exchange mechanism, ${ }^{11}$ we know that as the $\mathrm{Mn}^{3+}-$ $\mathrm{O}^{2-} \mathrm{Mn}^{4+}$ bond angle tends toward $180^{\circ}$ there should be a greater orbital overlap. This greater overlap leads to an increased extent of magnetic exchange, then suggesting a correlation between the percentage weight of the orthorhombic crystal structure, and the MCE as observed from the induction heating experiments. However this correlation is not observed from these results, showing that the bond angle does not appear to be the determining factor in the magnetic heating of this range of doped 
manganate perovskites. Previous work has investigated the effect of crystallite size on the MCE within the same family of doped materials. ${ }^{24}$ We conclude that the crystallite size is again a determining parameter in the observed MCE, regardless of the family of materials.

\subsection{Magnetic measurements}

Figure 9 shows the magnetic susceptibility of the materials as determined by the molar magnetisation divided by the applied magnetic field strength with respect to temperature. All samples show a ferromagnetic to paramagnetic transition, with the zero-field cooled and field cooled susceptibilities coinciding in the high temperature regime. As can be seen from Figure 9 , the Curie temperature $\left(T_{c}\right)$ is significantly below room temperature for LCMO40 and significantly above room temperature for LSMO40, with an intermediate value for LBMO40; the determined Curie temperatures are shown in Table 4. A shallow transition region is observed for LSMO40, exhibiting multiplicity as two slight inflections are observed on each graph. These two inflections in the magnetic transition region of the susceptibility measurements indicates that LSMO40 contains two ferromagnetic phases with two different stoichiometries. Each stoichiometry has its own $T_{c}$ which is why we see the inflections on the graph. As previously mentioned, we were not able to identify these stoichiometries either by trialling different model stoichiometries used for the model structures in the Rietveld analysis, or by EDX. LCMO40 and LBMO40 show steeper transition regions from ferromagnetic to paramagnetic, with no evidence of multiplicity. Hence LCMO40 and LBMO40 are more likely to be present in ferromagnetic phases of one stoichiometry. 
Table 4 shows the corresponding $T_{c}$ 's which were calculated from the susceptibility measurements. Usually, $T_{c}$ is estimated through the temperature derivative of the magnetisation in the transition region. As multiplicity in the magnetic susceptibility measurements is observed for LSMO40, this leads to a skewed derivative of magnetisation and hence a less definite estimation $T_{c}$. Thus the $T_{c}$ was estimated for each sample in this work using the Arrott plot method. ${ }^{25}$ The Arrott plot method involves plotting the inverse of magnetic susceptibility, against the square of magnetisation with respect to temperature. This gives a more definite identification of the $T_{c}$ where the two curves overlap as shown in Figure 6 in the Supplementary Information. For LBMO40 and LCMO40, $\mathrm{T}_{c}$ 's of $312 \mathrm{~K}$ and $262 \mathrm{~K}$ respectively have been identified in keeping with the literature. ${ }^{26,27}$ These low $T_{c}$ 's are in line with neither material exhibiting significant magnetic hyperthermia at room temperature.

As discussed previously, a positive MCE is reported to be associated with a ferromagnetic to paramagnetic transition ${ }^{13,14}$, with an inverse MCE reported to be associated with a paramagnetic to ferromagnetic transition..$^{28,29}$ From Figure 9 we can see that at room temperature LSMO40 and LBMO40 are present in the ferromagnetic state, with LCMO40 in the paramagnetic state. Thus, the application of a magnetic field in the heating experiments causes LSMO40 and LBMO40 to heat up and undergo ferromagnetic to paramagnetic transitions and exhibiting a positive MCE in the process. Guo et al. noted that smaller dopant ions in perovskite manganate structures contributed to larger magnetoelastic effects such as thermal expansion. ${ }^{30}$ Thus a sharper changing of magnetization near the Curie temperature would be observed, which is in keeping with the sharpening of the transition gradients in Figure 9 from LBMO40 to LCMO40. ${ }^{30}$ This is highlighted using the first differential of the zero-field cooled magnetic susceptibility 
measurements against temperature to describe the transition gradient. The largest change in the ferromagnetic to paramagnetic transition gradient for the dopant ion smaller than $\mathrm{La}^{3+}$ LCMO40 is -0.07 emu mol${ }^{-1} \mathrm{~K}^{-1}$ at $354 \mathrm{~K}$ compared with a dopant ion larger than $\mathrm{La}^{3+}, \mathrm{LBMO}^{2} 0$ where this value only reaches -0.05 emu $\mathrm{mol}^{-1} \mathrm{~K}^{-1}$ at $298 \mathrm{~K}$. The maximal gradient of the ferromagnetic to paramagnetic transition decreases again with increasing ionic dopant radii for LSMO40 (-0.04 emu mol ${ }^{-1} \mathrm{~K}^{-1}$ between $\left.352-360 \mathrm{~K}\right)$, although cautious comparison is made with the gradients of LBMO40 and LCMO40 as we acknowledge that more than one magnetic phase is present in this sample.

From the heating experiments we can see that LCMO40 exhibits reduced magnetic heating, but there is no paramagnetic to ferromagnetic or ferrimagnetic transition evident from the magnetic susceptibility measurements to indicate that this is magnetic cooling, and is a result of an inverse MCE. Instead, the LCMO40 sample remains in a paramagnetic state at room temperature. It is more likely that the latent heat has been used by the material to undergo a crystal structure transformation, which is why the observed magnetic heating for LCMO40 is reduced compared with the blank.

In Figures $10 \mathrm{a}$ and $10 \mathrm{~b}$ we see the comparisons of hysteresis loops at $100 \mathrm{~K}$ for LSMO40, LBMO40 and LCMO40 from which the characteristic hysteretic parameters are obtained and presented in Table 4. We can see that both LCMO40 and LSMO40 are greater in terms of both their coercivity and remnant magnetisation, than that of LBMO40. Hence we can describe LCMO40 and LSMO40 as harder ferromagnets than LBMO40 at $100 \mathrm{~K}$. This would suggest that the greater difference in A-site dopant radii compared to $\mathrm{La}^{3+}$ for LCMO40 and LSMO40 may lead to increasing difficulty in reversal of the magnetisation at $100 \mathrm{~K}$, with LSMO40 displaying this to the largest extent. Of 
course, these magnetisation measurements occur using a static field so no direct comparison may be made with the alternating field conditions used in the induction heating experiments to elucidate the MCE. However the variation in coercivity does appear to correlate with our observations for the MCE in the induction heating profiles, where there is a greater deviation for the LCMO40 (negative) and LSMO40 (positive) samples compared with the blank, than that of LBMO40. However the magnetic data does not help fully explain why the LCMO40 exhibits reduced magnetic heating when it is paramagnetic at room temperature in contrast to LSMO40 which exhibits enhanced magnetic heating.

In order to explain the observed relative magnetic 'cooling' for paramagnetic LCMO40, we can consider the change in heat capacity of the material with temperature, or the possibility of an additional crystal structure transition. Heat capacity is a measure of the change in internal energy of the material with observed temperature change and it is the sum of magnetic, lattice and electronic contributions. Where we would see a considerable change in internal energy such as in the vicinity of a transition temperature such as $T_{c}$ we would also expect to see anomalous behaviour in the heat capacity of the material. During the induction heating measurements, the LCMO40 sample is above its $T_{c}$ of $262 \mathrm{~K}$. It is therefore in the paramagnetic state, meaning that its magnetic contribution to the heat capacity is minimal. There may however have been a change in the lattice heat capacity as a result of a crystal structure transformation induced by the latent heat in the system. As previously mentioned, a change of magnetic (e.g. ferromagnetic to paramagnetic) structure can often be accompanied by a change in crystal structure (e.g. orthorhombic to rhombohedral). The latent heat necessary for the change in crystal structure would 
not have been dissipated as a result. This would explain the observed relative reduction in magnetic heating compared with the blank, as observed from the induction heating experiment.

\section{Conclusions}

We synthesised $\mathrm{La}_{1-\mathrm{x}} \mathrm{Ca}_{\times} \mathrm{MnO}_{3}$ and $\mathrm{La}_{1-\mathrm{x}} \mathrm{Ba}_{\times} \mathrm{MnO}_{3}$ for the first time using the modified peroxide sol-gel synthesis previously used in the synthesis of $\mathrm{La}_{1-x} \mathrm{Sr}_{x} \mathrm{MnO}_{3}$ at various dopant levels $(x=0.25,0.35$ and 0.4$) .{ }^{8}$ We were able to see that by increasing the A-site dopant radii (relative to $\mathrm{La}^{3+}$ ), we increased the positive magnetocaloric effect as measured by induction heating experiments. However, by decreasing the A-site dopant radii (relative to $\mathrm{La}^{3+}$ ), we observed reduced magnetic heating or in other words a magnetic 'cooling' effect relative to a blank. The trend of diminishing SAR from LSMO40, LBMO40, and LCMO40 was visible for the heating curves, which was consistent with the trend visible for the characteristic absorbance of the $\mathrm{Mn}-\mathrm{O}$ bond in each of the materials, which highlights the benefits of the use of IR-spectroscopy as a predictive tool.

This work also suggests that an alternative approach may be needed when considering materials as potential mediators for magnetic fluid hyperthermia. On the one hand, it is good to have MNPs with a low Curie temperature (e.g., to avoid overheating). On the other hand, a complex MCE, including relative magnetic cooling, can result from approaching the Curie temperature. Thus, in order to obtain effective mediators for a particular MCE related application, thorough systematic studies involving both direct MCE measurements, in addition to magnetisation data are necessary. 


\section{Acknowledgements}

Katherine McBride and Suzanne Bennington-Gray would like to acknowledge financial support from the Department of Education and Learning Northern Ireland (DEL-NI) and Engineering and Physical Sciences Research Council (ESPRC) respectively for PhD studentships. The authors also acknowledge the help of Professor David Rooney and Christopher McCallum for their help with the induction heating experiments.

\section{References}

1 N. Labhasetwar, G. Saravanan, S. K. Megarajan, N. Manwar, R. Khobragade, P. Doggali and F. Grasset, Science and Technology of Advanced Materials, 2015, 16, 036002.

2 Y. Doi, K. Matsuhira and Y. Hinatsu, Journal of Solid State Chemistry, 2002, 165, 317-323.

3 M. Ye, X. Wen, M. Wang, J. locozzia, N. Zhang, C. Lin and Z. Lin, Materials Today, 2015, 18, 155-162.

4 S. Vasseur, E. Duguet, J. Portier, G. Goglio, S. Mornet, E. Hadová, K. Knížek, M. Maryško, P. Veverka and E. Pollert, J Magn Magn Mater, 2006, 302, 315-320 (DOI:http://dx.doi.org/10.1016/j.jmmm.2005.09.026).

5 S. Louguet, B. Rousseau, R. Epherre, N. Guidolin, G. Goglio, S. Mornet, E. Duguet, S. Lecommandoux and C. Schatz, Polym. Chem., 2012, 3, 1408-1417

(DOI:10.1039/C2PY20089A).

6 E. Pollert, P. Veverka, M. Veverka, O. Kaman, K. Záveta, S. Vasseur, R. Epherre, G. Goglio and E. Duguet, Progress in Solid State Chemistry, 2009, 37, 1-14.

7 O. Kaman, P. Veverka, Z. Jirák, M. Maryško, K. Knížek, M. Veverka, P. Kašpar, M. Burian, V. Šepelák and E. Pollert, Journal of Nanoparticle Research, 2011, 13, 1237-1252.

8 K. McBride, J. Cook, S. Gray, S. Felton, L. Stella and D. Poulidi, CrystEngComm, 2016, 18, 407-416.

9 R. Epherre, C. Pepin, N. Penin, E. Duguet, S. Mornet, E. Pollert and G. Goglio, J. Mater. Chem., 2011, 21, 14990-14998 (DOI:10.1039/C1JM12137E). 
10 R. D. Shannon, Acta Crystallographica Section A: Crystal Physics, Diffraction, Theoretical and General Crystallography, 1976, 32, 751-767.

11 C. Zener, Physical Review, 1951, 82, 403.

12 B. D. Cullity and C. D. Graham, Introduction to Magnetic Materials, Wiley-IEEE Press, Hoboken, New Jersey, 2009.

13 A. Asamitsu, Y. Moritomo, Y. Tomioka, T. Arima and Y. Tokura, Nature, 1995, 373, 407 409.

14 A. Urushibara, Y. Moritomo, T. Arima, A. Asamitsu, G. Kido and Y. Tokura, Phys. Rev. B, 1995, 51, 14103-14109.

15 S. Liu, X. Tan, K. Li and R. and Hughes, Ceram. Int., 2002, 28, 327-335 (DOI:http://dx.doi.org/10.1016/S0272-8842(01)00098-0).

16 C. H. Chen, H. Kruidhof, H. J. M. Bouwmeester and A. J. Burggraaf, Materials Science and Engineering: B, 1996, 39, 129-132 (DOl:http://dx.doi.org/10.1016/0921-5107(96)01582-6).

17 L. Nalbandian, A. Evdou and V. Zaspalis, Int J Hydrogen Energy, 2009, 34, 7162-7172 (DOI:http://dx.doi.org/10.1016/j.ijhydene.2009.06.076).

18 M. Phan and S. and Yu, J Magn Magn Mater, 2007, 308, 325-340.

19 T. Degen, M. Sadki, E. Bron, U. König and G. Nénert, Powder Diffraction, 2014, 29, S13-S18.

20 R. R. Wildeboer, P. Southern and Q. A. and Pankhurst, J. Phys. D, 2014, 47, 495003.

21 A. L. A. da Silva, L. da Conceição, A. M. Rocco and M. M. V. M. Souza, Cerâmica, 2012, 58, 521-528.

22 B. V. Slobodin, E. V. Vladimirova, S. L. Petukhov, L. L. Surat and I. A. Leonidov, Inorganic materials, 2005, 41, 869-875.

23 V. Markovich, A. Wisniewski and H. Szymczak, in Handbook of Magnetic Materials, ed. K. H. J. Buschow, Elsevier B.V, Great Britain, 2014, p. 1-201.

24 A. Gaur and G. D. Varma, Journal of Physics: Condensed Matter, 2006, 18, 8837.

25 A. Arrott, Physical Review, 1957, 108, 1394.

26 X. X. Zhang, J. Tejada, Y. Xin, G. F. Sun, K. W. Wong and X. Bohigas, Appl. Phys. Lett., 1996, 69, 3596-3598.

27 X. Bohigas, J. Tejada, M. Marínez-Sarrión, S. Tripp and R. Black, J Magn Magn Mater, 2000, 208, 85-92. 
28 T. Krenke, E. Duman, M. Acet, E. F. Wassermann, X. Moya, L. Mañosa and A. Planes, Nature materials, 2005, 4, 450-454.

29 P. J. Von Ranke, N. A. De Oliveira, B. P. Alho, E. J. R. Plaza, V. S. R. De Sousa and L. and Caron, Journal of Physics: Condensed Matter, 2009, 21, 056004.

30 Z. Guo, W. Yang, Y. Shen and Y. Du, Solid State Commun., 1998, 105, 89-92.

31 M. A. Islam, J. M. Rondinelli and J. E. Spanier, Journal of Physics: Condensed Matter, 2013, 25, 175902.

32 D. Green and K. Neumann, arXiv preprint arXiv:1105.2700, 2011, . 
Table 1 - Characterisations presented for the materials presented in this paper.

\begin{tabular}{|c|c|c|c|c|c|c|c|c|c|}
\hline Sample & $\begin{array}{c}\text { Sample } \\
\text { Code }\end{array}$ & EDX & XRD & IR & $\begin{array}{l}\text { Induction } \\
\text { Heating }\end{array}$ & SEM & $\begin{array}{l}\text { M vs T } \\
\text { (SQUID) }\end{array}$ & $\begin{array}{c}\text { Hysteresis } \\
\text { (SQUID) }\end{array}$ & EDX Stoichiometry \\
\hline $\mathrm{LaMnO}_{3}$ & LMO & & $\checkmark$ & $\checkmark$ & $\checkmark$ & & & & ------- \\
\hline $\mathrm{La}_{0.6} \mathrm{Sr}_{0.4} \mathrm{MnO}_{3}$ & LSMO40 & $\checkmark$ & $\checkmark$ & $\checkmark$ & $\checkmark$ & $\checkmark$ & $\checkmark$ & $\checkmark$ & $\mathrm{La}_{0.62} \mathrm{Sr}_{0.38} \mathrm{MnO}_{3}$ \\
\hline $\mathrm{La}_{0.65} \mathrm{Sr}_{0.35} \mathrm{MnO}_{3}$ & LSMO35 & & & & $\checkmark$ & & & & \\
\hline $\mathrm{La}_{0.75} \mathrm{Sr}_{0.25} \mathrm{MnO}_{3}$ & LSMO25 & & & & $\checkmark$ & & & & \\
\hline $\mathrm{La}_{0.6} \mathrm{Ba}_{0.4} \mathrm{MnO}_{3}$ & LBMO40 & $\checkmark$ & $\checkmark$ & $\checkmark$ & $\checkmark$ & $\checkmark$ & $\checkmark$ & $\checkmark$ & $\mathrm{La}_{0.62} \mathrm{Ba}_{0.38} \mathrm{MnO}_{3}$ \\
\hline $\mathrm{La}_{0.65} \mathrm{Ba}_{0.35} \mathrm{MnO}_{3}$ & LBMO35 & & & & $\checkmark$ & & & & \\
\hline $\mathrm{La}_{0.75} \mathrm{Ba}_{0.25} \mathrm{MnO}_{3}$ & LBMO25 & & & & $\checkmark$ & & & & \\
\hline $\mathrm{La}_{0.6} \mathrm{Ca}_{0.4} \mathrm{MnO}_{3}$ & LCMO40 & $\checkmark$ & $\checkmark$ & $\checkmark$ & $\checkmark$ & & $\checkmark$ & $\checkmark$ & $\mathrm{La}_{0.66} \mathrm{Ca}_{0.34} \mathrm{MnO}_{3}$ \\
\hline $\mathrm{La}_{0.65} \mathrm{Ca}_{0.35} \mathrm{MnO}_{3}$ & LCMO35 & & & & $\checkmark$ & & & & \\
\hline $\mathrm{La}_{0.75} \mathrm{Ca}_{0.25} \mathrm{MnO}_{3}$ & LCMO25 & & & & $\checkmark$ & & & & \\
\hline
\end{tabular}


Table 2 - Lattice parameters and atomic coordinates for (a) orthorhombic (Pnma) ${ }^{31}$ and (b) rhombohedral $(R-3 c)^{32}$ crystal structures. These literature values were input parameters for Rietveld analysis of XRD data as they best fit the experimental data. (The Wycoff positions provide information about where the atoms of a compound can be found in a crystal and are a standard notation supported by the International Union of Crystallography.)

(a) Orthorhombic (Pnma) atomic coordinates and lattice parameters

\begin{tabular}{ccccc}
\hline Atom & $\begin{array}{c}\text { Wycoff } \\
\text { Position }\end{array}$ & $x$ & $y$ & $z$ \\
\hline A & $4 c$ & 0.55 & 0.25 & 0 \\
B & $4 a$ & 0 & 0 & 0 \\
$O(1)$ & $4 c$ & -0.011 & 0.25 & -0.071 \\
$O(2)$ & $8 d$ & 0.309 & 0 & 0.225 \\
\hline
\end{tabular}

Lattice cell parameters ( $\AA$ ): for LMO, LSMO40 31 and LBMO40; $a=5.5743, b=7.695$ and $c=$ 5.537 , for LCMO40; $a=5.452, b=7.678$, and $c=5.437$.

(b) Rhombohedral (R-3c) lattice parameters and atomic coordinates

\begin{tabular}{ccccc}
\hline Atom & $\begin{array}{c}\text { Wycoff } \\
\text { Position }\end{array}$ & $x$ & $y$ & $z$ \\
\hline A & $6 a$ & 0 & 0 & 0.25 \\
B & $6 \mathrm{~b}$ & 0 & 0 & 0 \\
O & $18 \mathrm{e}$ & 0.5511 & 0 & 0.25 \\
\hline
\end{tabular}

Lattice cell parameters ( $(\AA)$ : for $L M O$ and $\mathrm{LSMO}^{32}{ }^{32} ; \mathrm{a}=\mathrm{b}=5.5212$ and $\mathrm{c}=13.37908$, for CSMO40; $a=b=5.3$, and $c=13.016$, for LCMO40 and LBMO40; $a=b=5.477$ and $c=13.310$ 
Table 3 - Structural Information generated from XRD patterns in Figure 2 using Rietveld analysis for LBMO40, LCMO40, and LSMO40, compared with LMO. ( $R_{w}$ is the weighted R-value, $R_{\exp }$ is the expected R-value, $R_{b r a g g}$ is the specific $R$-value for a particular phase in the refinement, Gof is the Goodness of Fit). Angles $\alpha, \beta$ and $\gamma$ were were not allowed to vary during the refinement. The corresponding angles were $\alpha=\beta=\gamma=90^{\circ}$ for Pnma and $\alpha=\beta=90^{\circ}$ and $\gamma=120^{\circ}$ for R-3c. Crystallite size is estimated with the Scherrer equation, using the (002) reflection for the Pnma crystal phase and the (104) reflection for the R-3c phase.

\begin{tabular}{|c|c|c|c|c|c|c|c|c|c|c|c|c|}
\hline Sample & Crystal System & a / $\AA$ & b / $\AA$ & $c / \AA$ & $V / \AA$ & $\begin{array}{l}\text { Space } \\
\text { group }\end{array}$ & $\mathrm{R}_{\mathrm{w}}$ & $R_{\text {exp }}$ & $R_{\text {bragg }}$ & Gof & $\begin{array}{c}\text { Wt. } \\
\text { percent. / } \\
\%\end{array}$ & $\begin{array}{c}\text { Crystallite } \\
\text { size }(\mathrm{nm})\end{array}$ \\
\hline \multirow{2}{*}{ LBMO40 } & Orthorhombic & 5.9401 & 8.3673 & 5.1261 & 254.8 & Pnma & \multirow{2}{*}{13.0} & \multirow[t]{2}{*}{3.2} & 43.4 & \multirow{2}{*}{16.3} & 20.7 & 10.7 \\
\hline & Rhombohedral & 5.5109 & 5.5109 & 13.3543 & 357.8 & $R-3 c$ & & & 5.3 & & 79.3 & 29.0 \\
\hline \multirow{2}{*}{ LCMO40 } & Orthorhombic & 5.4230 & 7.6916 & 5.4346 & 226.7 & Pnma & \multirow{2}{*}{5.6} & \multirow{2}{*}{3.0} & 18.9 & \multirow{2}{*}{3.4} & 42.0 & 14.1 \\
\hline & Rhombohedral & 5.4698 & 5.4698 & 13.3559 & 346.1 & $R-3 c$ & & & 8.3 & & 58.0 & 30.2 \\
\hline \multirow{2}{*}{ LSMO40 } & Orthorhombic & 5.44819 & 7.7501 & 5.45624 & 230.4 & Pnma & \multirow{2}{*}{6.1} & \multirow{2}{*}{2.7} & 29.5 & \multirow{2}{*}{5.03} & 31.2 & 16.5 \\
\hline & Rhombohedral & 5.51086 & 5.5109 & 13.3543 & 351.2 & $R-3 c$ & & & 9.57 & & 68.8 & 37.4 \\
\hline
\end{tabular}


Table 4 - Parameters derived from the magnetisation measurements for LSMO40, LCMO40, and LBMO40 ( $T_{c}$ - Curie temperature calculated using the Arrott plot method ${ }^{25} ; \mathrm{M}_{\mathrm{s}}$ saturation magnetisation, $\mathrm{H}_{\mathrm{c}}$ - coercivity, and $\mathrm{M}_{\mathrm{r}}$ - remnant magnetisation are measured at $100 \mathrm{~K})$.

\begin{tabular}{ccccc}
\hline Sample & $\begin{array}{c}\mathrm{M}_{\mathrm{s}} \\
\text { emu/mol }\end{array}$ & $\begin{array}{c}\mathrm{H}_{\mathrm{c}} \\
\text { Oe }\end{array}$ & $\begin{array}{c}\mathrm{M}_{\mathrm{r}} \\
\text { emu/mol }\end{array}$ & $\begin{array}{c}\mathrm{T}_{\mathrm{c}} \\
\mathrm{K}\end{array}$ \\
\hline LSMO40 & 3500 & 100 & 175 & 352 \\
LBMO40 & 3800 & 80 & 162 & 312 \\
LCMO40 & 4800 & 170 & 342 & 262 \\
\hline
\end{tabular}




\section{Figure Captions List}

Figure 1 - The effect of doping with smaller (a) and larger (c) A-site cations on the ideal structure of pseudo-cubic perovskites of the type $\mathrm{ABO}_{3}$ (b).

Figure 2 - X-ray Diffraction Patterns for the range of doped manganite materials containing common lanthanum cations in A-site positions where $\mathrm{x}=0.4$.

Figure 3 - Scanning Electron Micrographs of (a) LBMO40 (b) and LSMO40.

Figure 4 - FTIR spectra for LBMO40, and LCMO40, compared with LSMO40.

Figure 5 - The relationship between the percentage difference in radii of A-site cations, the mean average crystallite diameter of the Pnma and R-3c phases shown in Table 2, and MnO absorption wavenumber for LBMO40, and LCMO40, compared with LSMO40.

Figure 6 - (a) Heating curves of LBMO40, LCMO40, and LSMO40, where aqueous dispersions of $5 \mathrm{mg} \mathrm{mL}^{-1}$ were used and comparison is made with a blank. From this, (b) shows the heating curves with the blank subtracted to show the enhanced magnetic heating caused by the LSMO40 and LBMO40 samples, with reduced magnetic heating shown for LCMO40 relative to the blank.

Figure 7 - Specific Absorption Rates of LBMO, LCMO and LSMO (at $x=0.25,0.35$ and 0.4 ) compared with the blank.

Figure 8 - Relationship between the wavenumber of the $\mathrm{Mn}-\mathrm{O}$ bond with the Specific Absorption Rate for LSMO40, LBMO40 and LCMO40 compared against the undoped parent LMO. 
Figure 9 - Magnetic susceptibly of LBMO40, and LCMO40, compared with LSMO40. (Solid lines represent Field Cooled (FC) measurement and dashed lines represent Zero-Field Cooled (ZFC) measurements.)

Figure 10 - Hysteresis loops for LBMO40, and LCMO40, compared with LSMO40 for all samples, at $100 \mathrm{~K}(\mathrm{~b})$ shows an enlargement of the section around the origin of (a); the field was varied from $+10 \mathrm{kOe}$ to $-10 \mathrm{kOe}$. 
Figure 1

(a)

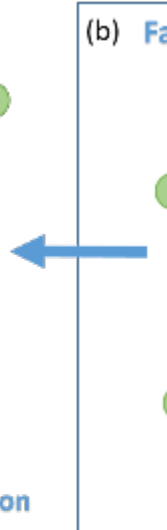

b) Face-centred cubic perovskite

(c)

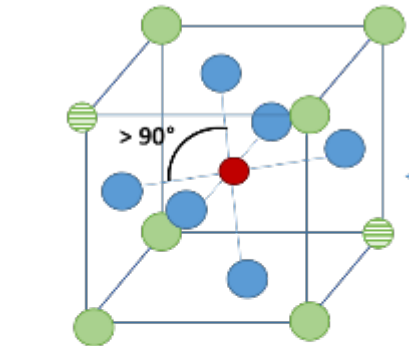

Doped with Smaller A-site cation e.g. $\mathrm{La}_{1-x} \mathrm{Ca}_{x} \mathrm{MnO}_{3}$

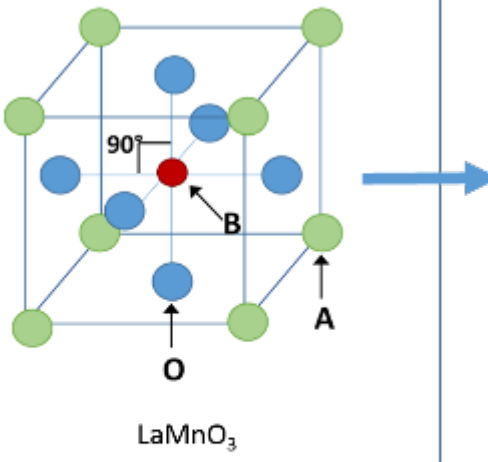

Doped with Larger A-site cation e.g. $\mathrm{La}_{1-\mathrm{x}} \mathrm{Sr}_{\mathrm{x}} \mathrm{MnO}_{3}$ $\mathrm{La}_{1-x} \mathrm{Ba}_{\mathrm{x}} \mathrm{MnO}_{3}$

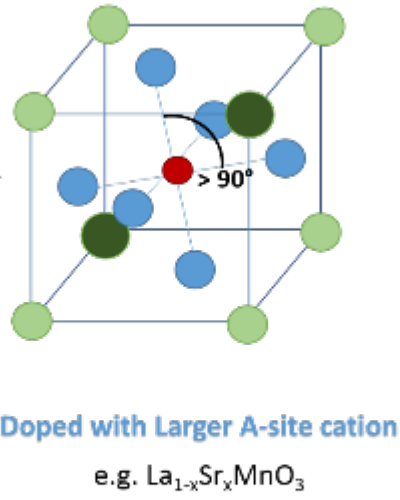

B-Manganese

o-Oxygen 
Figure 2

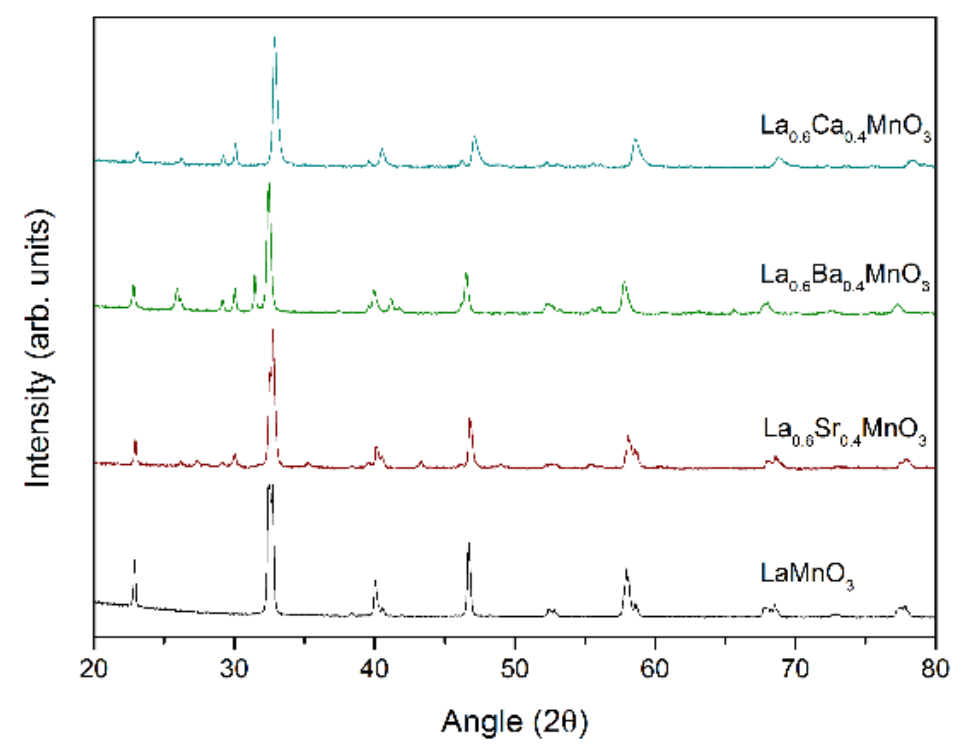


Figure 3

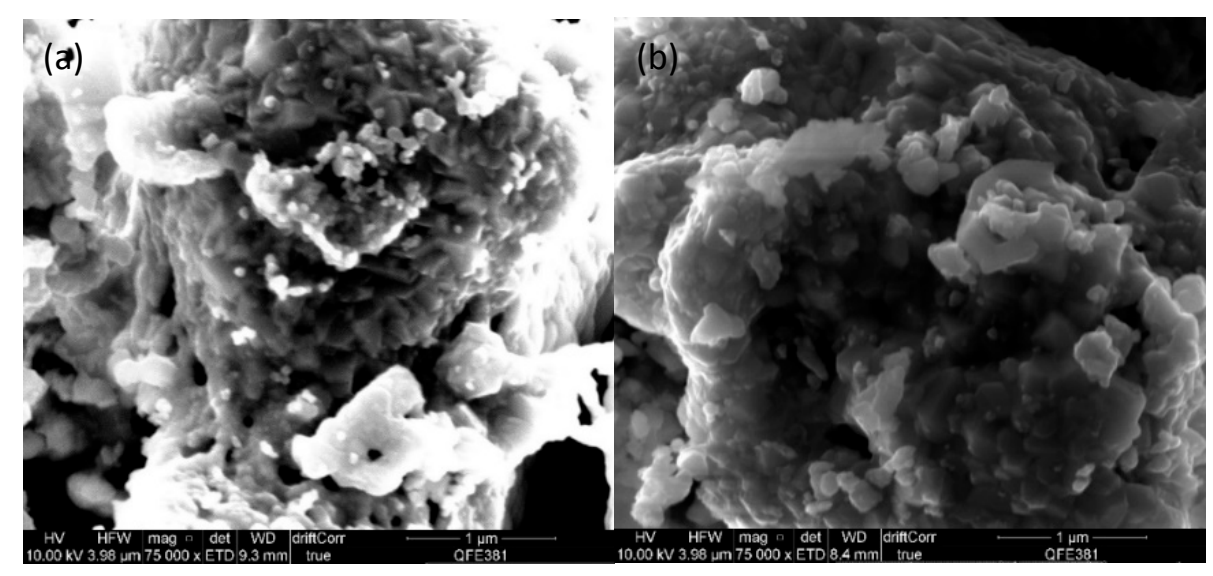


Figure 4

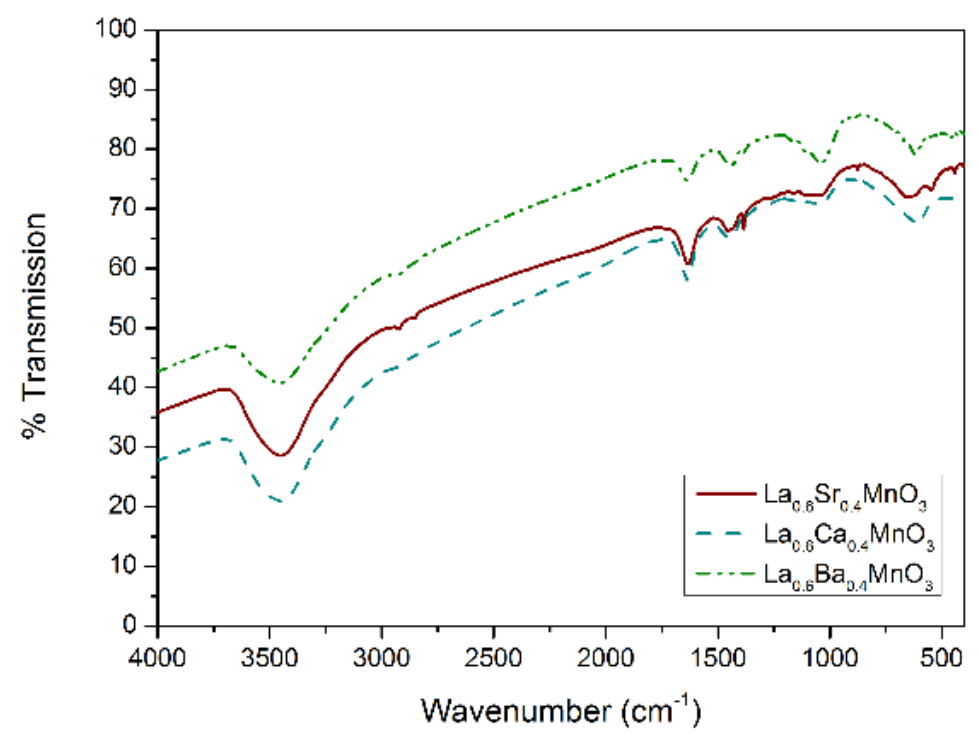


Figure 5

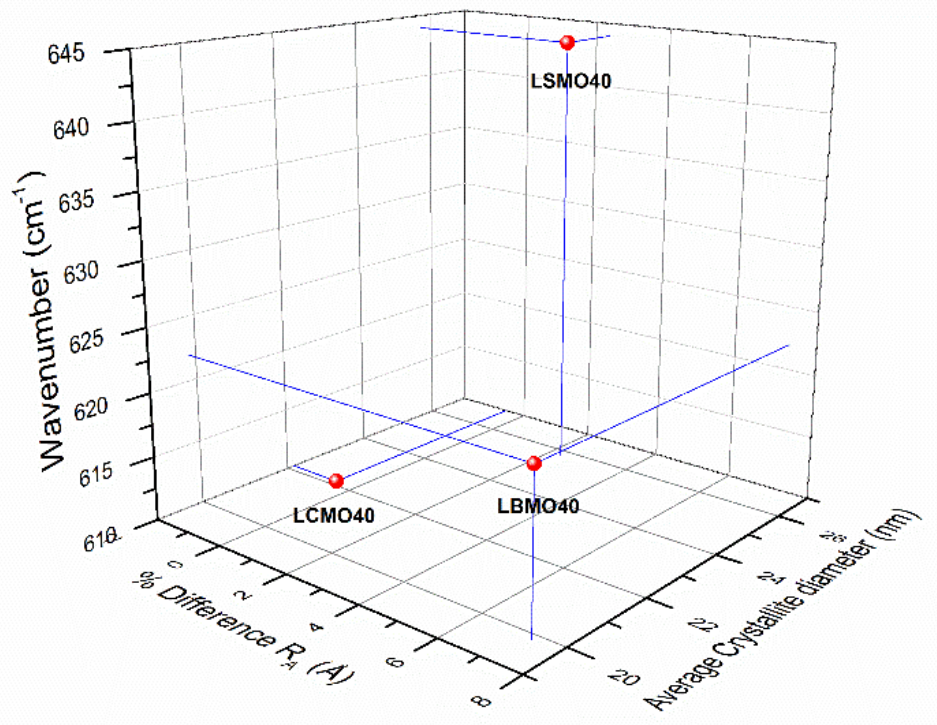


Figure 6

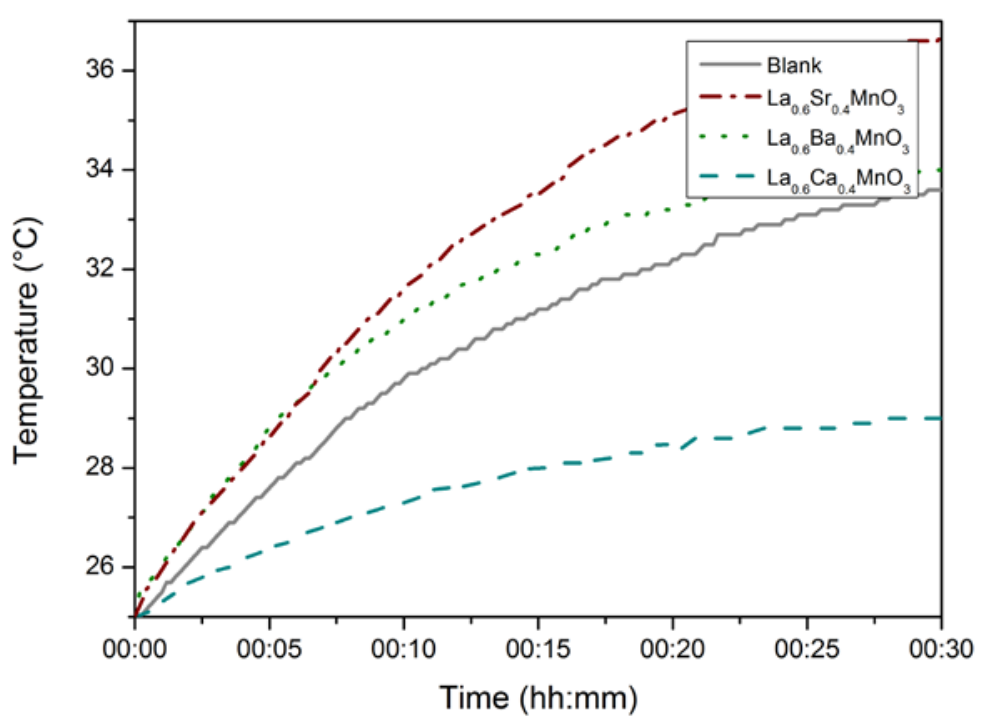

(a)

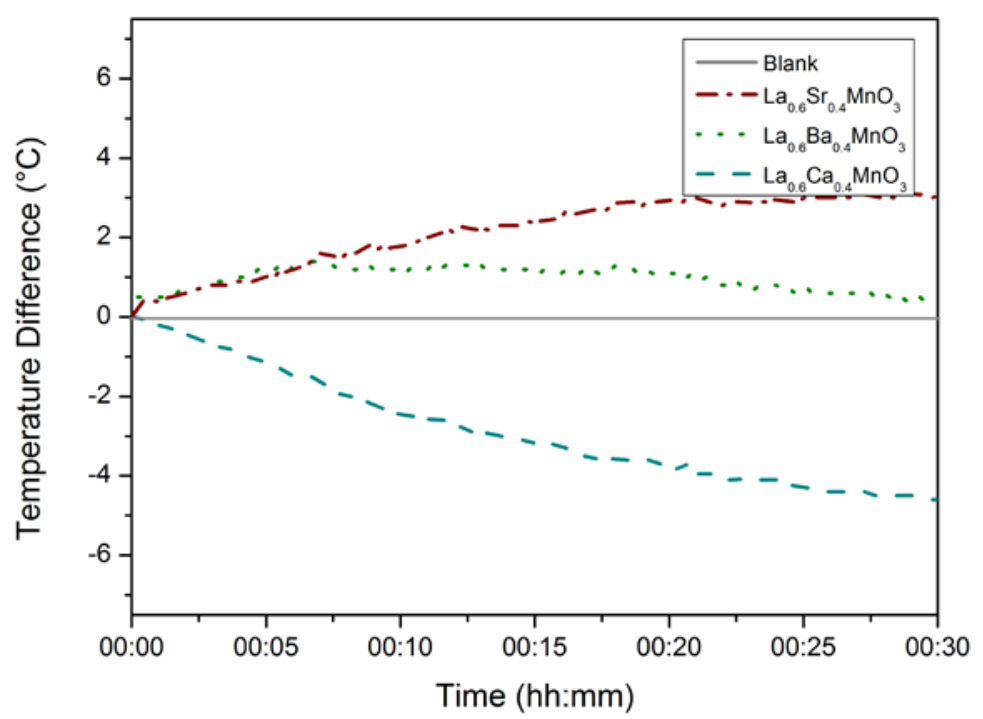

(b) 
Figure 7

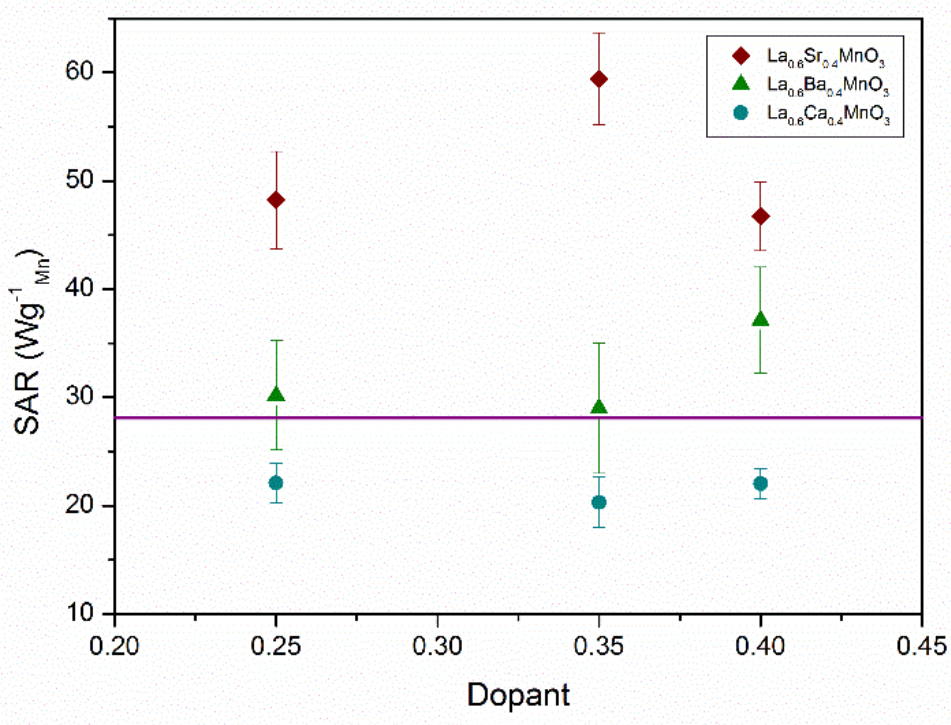


Figure 8

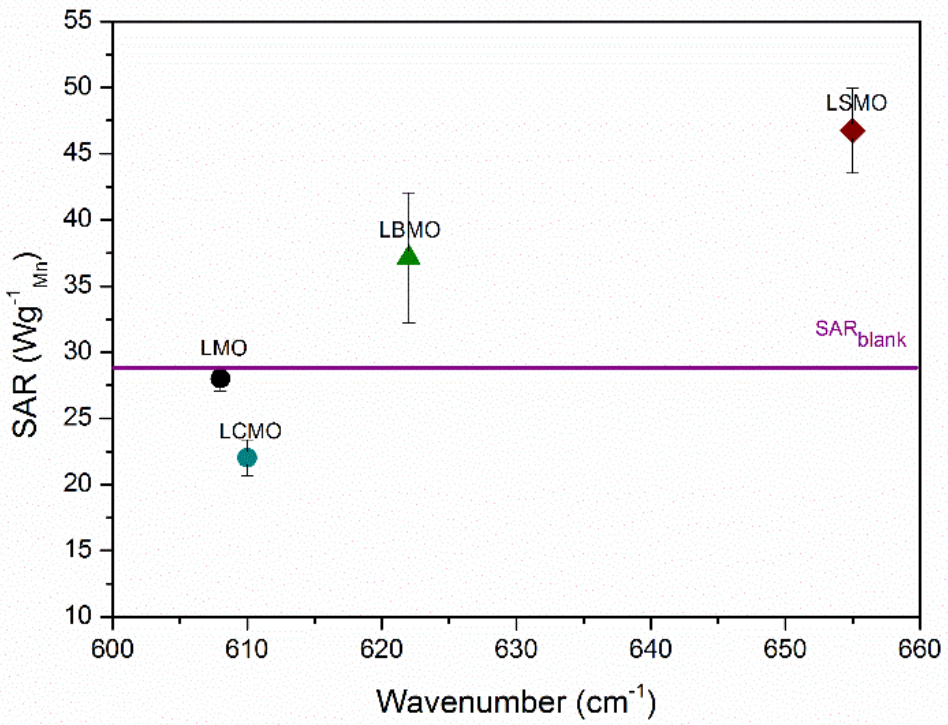


Figure 9

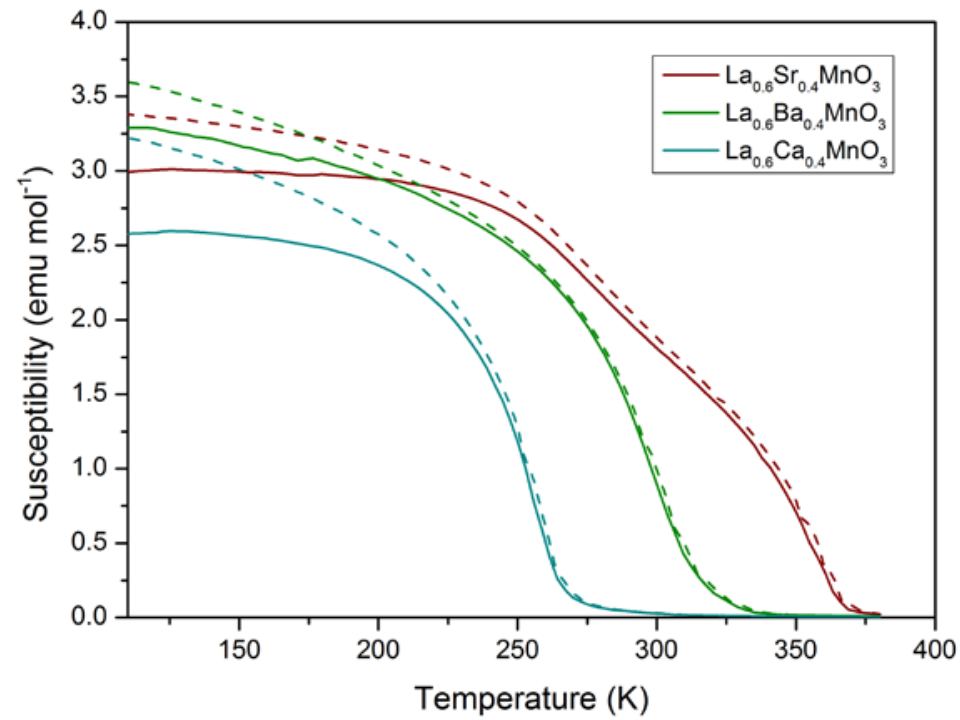


Figure 10

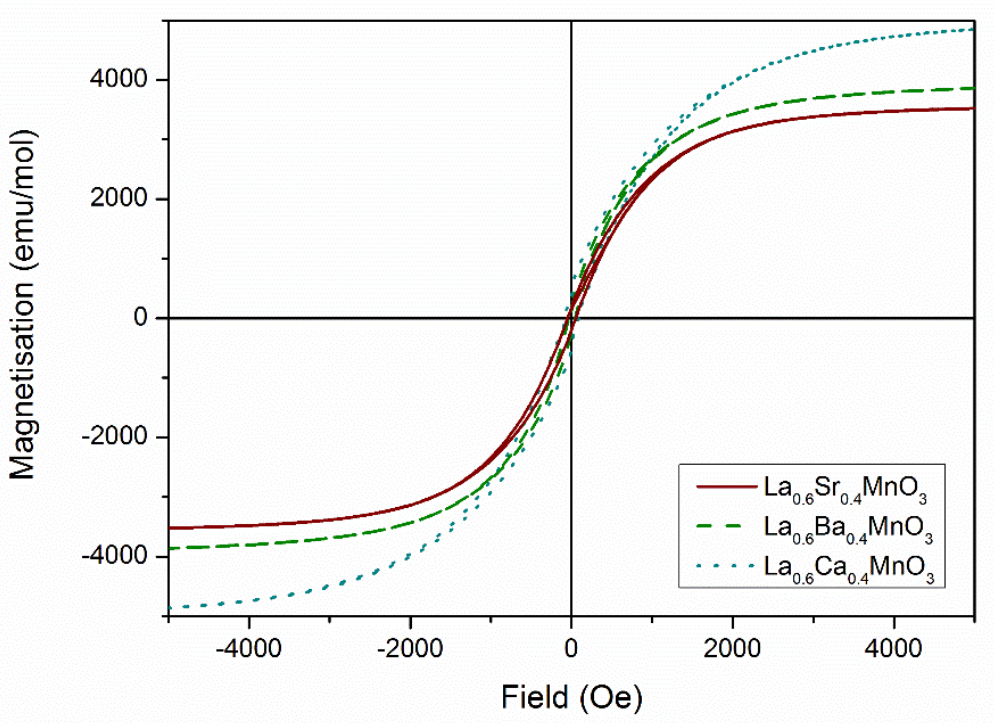

(a)

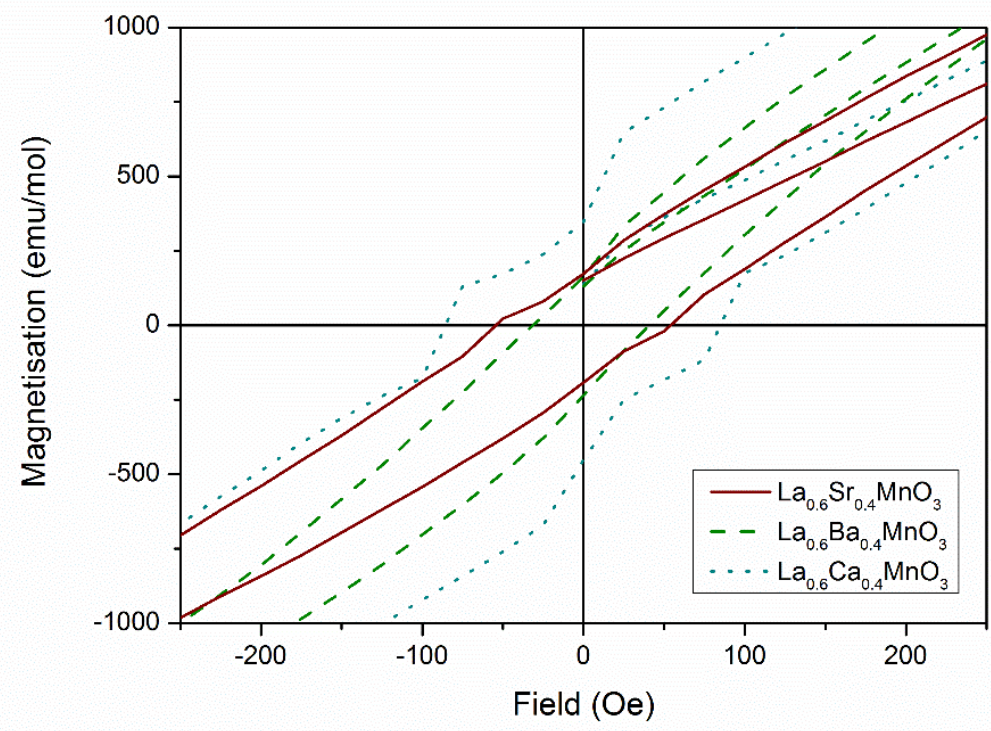

(b) 